Article

\title{
Prognostic Impact of Tumor-Associated Macrophages on Survival Is Checkpoint Dependent in Classical Hodgkin Lymphoma
}

\author{
Kristiina Karihtala ${ }^{1,2}$, Suvi-Katri Leivonen ${ }^{1,2}$, Oscar Brück ${ }^{3,4} \mathbb{D}$, \\ Marja-Liisa Karjalainen-Lindsberg ${ }^{5}$, Satu Mustjoki ${ }^{3,4}{ }^{(D)}$, Teijo Pellinen ${ }^{6}$ and Sirpa Leppä ${ }^{1,2, * \mathbb{D}}$ \\ 1 Applied Tumor Genomics Research Program, Faculty of Medicine, University of Helsinki, 00014 Helsinki, \\ Finland; kristiina.karihtala@hus.fi (K.K.); suvi-katri.leivonen@helsinki.fi (S.-K.L.) \\ 2 Department of Oncology, Helsinki University Hospital Comprehensive Cancer Center, 00029 Helsinki, \\ Finland \\ 3 Translational Immunology Research Program and Department of Clinical Chemistry and Hematology, \\ University of Helsinki, 00014 Helsinki, Finland; oscar.bruck@helsinki.fi (O.B.); \\ satu.mustjoki@helsinki.fi (S.M.) \\ 4 Hematology Research Unit Helsinki, Helsinki University Hospital Comprehensive Cancer Center, \\ 00029 Helsinki, Finland \\ 5 Department of Pathology, Helsinki University Hospital, 00029 Helsinki, Finland; \\ marja-liisa.karjalainen-lindsberg@hus.fi \\ 6 Institute for Molecular Medicine Finland (FIMM), 00014 Helsinki, Finland; teijo.pellinen@helsinki.fi \\ * Correspondence: sirpa.leppa@helsinki.fi; Tel.: +358-50-427-0820
}

Received: 4 March 2020; Accepted: 30 March 2020; Published: 4 April 2020

\begin{abstract}
Tumor microenvironment and immune escape affect pathogenesis and survival in classical Hodgkin lymphoma (cHL). While tumor-associated macrophage (TAM) content has been associated with poor outcomes, macrophage-derived determinants with clinical impact have remained undefined. Here, we have used multiplex immunohistochemistry and digital image analysis to characterize TAM immunophenotypes with regard to expression of checkpoint molecules programmed cell death ligand 1 (PD-L1) and indoleamine 2,3-dioxygenase 1 (IDO-1) from the diagnostic tumor tissue samples of $130 \mathrm{cHL}$ patients, and correlated the findings with clinical characteristics and survival. We show that a large proportion of TAMs express PD-L1 (CD68 ${ }^{+}$, median 32\%; M2 type $\mathrm{CD} 163^{+}$, median $22 \%$ ), whereas the proportion of TAMs expressing IDO- 1 is lower $\left(\mathrm{CD}^{+} 8^{+}\right.$, median $5.5 \%$; $\mathrm{CD}_{163^{+}}$, median $1.4 \%)$. A high proportion of PD-L1 and IDO-1 expressing TAMs from all TAMs $\left(\mathrm{CD} 68^{+}\right)$, or from $\mathrm{CD}_{163^{+}} \mathrm{TAMs}$, is associated with inferior outcome. In multivariate analysis with age and stage, high proportions of PD-L1 ${ }^{+}$and IDO- $1^{+}$TAMs remain independent prognostic factors for freedom from treatment failure (PD-L1 ${ }^{+} \mathrm{CD}_{8}{ }^{+} / \mathrm{CD}^{+} 8^{+}, \mathrm{HR}=2.63,95 \% \mathrm{CI} 1.17-5.88, p=0.019 ; \mathrm{IDO}-1^{+} \mathrm{CD} 68^{+} / \mathrm{CD} 68^{+}$, $\mathrm{HR}=2.48,95 \%$ CI 1.03-5.95, $p=0.042$ ). In contrast, proportions of PD-L1 ${ }^{+}$tumor cells, all TAMs or PD-L1 ${ }^{-}$and IDO-1 $1^{-}$TAMs are not associated with outcome. The findings implicate that adverse prognostic impact of TAMs is checkpoint-dependent in cHL.
\end{abstract}

Keywords: classical hodgkin lymphoma; tumor-associated macrophages; tumor microenvironment; checkpoint molecules; multiplex immunohistochemistry; survival

\section{Introduction}

Classical Hodgkin lymphoma (cHL) is characterized by unique cell composition of the tumor, where typically low numbers of neoplastic Hodgkin and Reed-Sternberg cells (HRS cells) are surrounded by abundant reactive inflammatory cells [1]. HRS cells express numerous immunoregulatory proteins 
that can shape the microenvironment and allow tumor cells to escape immune surveillance [2,3]. One example of this is immune evasion via the programmed cell death-1 (PD-1) pathway due to the genetic/genomic alterations of chromosome 9p24.1, which leads to increased expression of PD-1 ligand 1 and 2 (PD-L1 and PD-L2) in HRS cells [4] and T-cell exhaustion [5], and finally translates to poor survival in patients treated with chemotherapy [4].

Apart from HRS cells, PD-L1 and PD-L2 are expressed in the tumor microenvironment (TME) [6], and PD-L1 particularly in tumor-associated macrophages (TAMs), which are located physically in the vicinity of PD-L1 ${ }^{+}$HRS cells [7]. Macrophages also express other immunosuppressive molecules, such as indoleamine 2,3-dioxygenase (IDO-1), an enzyme responsible for catabolizing tryptophan into kynurenine metabolites [8]. IDO-1 activity can lead to the inhibition of T-cells by suppression of effector T-cell function and activation of regulatory T-cells [8,9], which is a potential mechanism enabling tumor cells to avoid host immune response. In cHL, both an increased proportion of PD-L1 ${ }^{+}$ leukocytes [10] and IDO expression in the TME cells in nodular sclerosis (NS) subtype [11] have been associated with inferior overall survival.

Several studies have demonstrated that high numbers of either $\mathrm{CD}^{+} 8^{+}$or $\mathrm{CD} 163^{+} \mathrm{TAM}$ translate to unfavorable survival in cHL [12-17]. There are also studies, however, in which this association has not been confirmed [18-21]. The purpose of this study is to digitally quantify TAM abundance and to characterize TAM immunophenotypes with regard to PD-L1 and IDO-1 expression from diagnostic cHL tumor samples, as well as to associate the findings with clinical characteristics and survival.

\section{Results}

\subsection{Patient Characteristics and Outcome}

The main multiplex immunohistochemistry (mIHC) cohort consisted of $130 \mathrm{cHL}$ patients whose demographics and outcome are described in Table 1 . The median age of the patients was 29 years, and the majority represented the NS subtype, had advanced stage, were negative for Epstein-Barr virus (EBV), had low International Prognostic Score (IPS), and were treated with doxorubicin, bleomycin, vinblastine and dacarbazine (ABVD), followed by radiotherapy. During the follow-up time, 28 patients relapsed and 10 died, six of them from cHL. The 5-year freedom from treatment failure (FFTF), disease-specific survival (DSS), and overall survival (OS) were $80 \%, 94 \%$ and $91 \%$, respectively.

Table 1. Patient demographics and outcome.

\begin{tabular}{cc}
\hline Characteristic & $n=\mathbf{1 3 0}(\mathbf{\%})$ \\
\hline Median follow-up time, months (range) & $55(7-229)$ \\
\hline Age (years) & $29(16-83)$ \\
\hline Median (range) & $116(89)$ \\
$\geq 60$ & $14(11)$ \\
\hline Sex & \\
\hline Male & $59(45)$ \\
Female & $71(55)$ \\
\hline Histologic subtype & $102(78)$ \\
Nodular sclerosis & $21(16)$ \\
Mixed cellularity & $6(5)$ \\
Lymphocyte-rich & $1(1)$ \\
Unclassified cHL &
\end{tabular}


Table 1. Cont.

\begin{tabular}{|c|c|}
\hline Characteristic & $n=130(\%)$ \\
\hline \multicolumn{2}{|l|}{ Stage } \\
\hline I-IIA & $56(43)$ \\
\hline IIB-IV & $73(56)$ \\
\hline NA & $1(1)$ \\
\hline \multicolumn{2}{|l|}{ EBV status } \\
\hline Negative & $89(69)$ \\
\hline Positive & $34(26)$ \\
\hline NA & $7(5)$ \\
\hline \multicolumn{2}{|l|}{ IPS } \\
\hline $0-3$ & $86(66)$ \\
\hline $4-7$ & $7(5)$ \\
\hline NA & $37(29)$ \\
\hline \multicolumn{2}{|l|}{ Treatment } \\
\hline ABVD & $41(32)$ \\
\hline $\mathrm{ABVD}+$ radiotherapy & $70(53)$ \\
\hline BEACOPPesc & $5(4)$ \\
\hline BEACOPPesc + radiotherapy & $4(3)$ \\
\hline ABVD + BEACOPPesc & $4(3)$ \\
\hline $\mathrm{CHOP}$ & $4(3)$ \\
\hline Other & $2(2)$ \\
\hline Radiotherapy * & $77(59)$ \\
\hline Relapses & $28(22)$ \\
\hline Deaths & $10(8)$ \\
\hline cHL related deaths & $6(60)$ \\
\hline 5-year FFTF & $80 \%$ \\
\hline 5-year DSS & $94 \%$ \\
\hline 5-year OS & $91 \%$ \\
\hline
\end{tabular}

* Including chemotherapy and radiotherapy and radiotherapy only. ABVD, doxorubicin, bleomycin, vinblastine, dacarbazine; BEACOPPesc, bleomycin, etoposide, doxorubicin, cyclophosphamide, vincristine, procarbazine, prednisone in escalated dose; CHOP, cyclophosphamide, doxorubicin, vincristine, prednisone; NA, not assigned; EBV, Epstein-Barr virus; IPS, International Prognostic Score; FFTF, freedom from treatment failure; DSS, disease-specific survival; OS, overall survival.

\subsection{Association of IDO-1, PD-L1, CD68, CD163 Gene Expressions with Outcome}

First, for screening purposes we measured mRNA expression levels of both macrophage markers (CD68 and CD163) and selected checkpoint molecules CD274 (gene encoding PD-L1), as well as IDO-1 from 88 diagnostic cHL samples. Then, we examined whether their gene expressions in the tumor tissue correlated with each other. $C D 274$ expression correlated positively with $C D 68(\rho=0.688, p<0.001)$ and to a lesser extent with $C D 163$ expression $(\rho=0.362, p=0.001)$. IDO-1 expression correlated with $C D 68$ expression $(\rho=0.386, p<0.001)$, whereas no correlation with $C D 163$ expression was found. Expressions of CD68 and CD163 correlated with each other $(\rho=0.549, p<0.001)$ (Figure S1a). Interestingly, when analyzed as continuous variables, high CD274 and IDO-1 expression translated to poor FFTF, and high IDO-1 expression also translated to poor DSS and OS. In addition, high CD68 expression correlated with inferior OS, whereas CD163 expression was not associated with outcome (Table 2). 
Table 2. Cox regression analysis as continuous variable at univariate level showing association of gene expression levels with FFTF, DSS and OS.

\begin{tabular}{cccccccccc}
\hline \multirow{2}{*}{ Gene Symbol } & \multicolumn{3}{c}{ FFTF } & \multicolumn{3}{c}{ DSS } & \multicolumn{3}{c}{ OS } \\
\cline { 2 - 10 } & HR & $\mathbf{9 5 \%}$ CI & $p$ & HR & $\mathbf{9 5 \% ~ C I ~}$ & $\boldsymbol{p}$ & HR & $\mathbf{9 5 \% ~ C I ~}$ & $\boldsymbol{p}$ \\
\hline CD274 (PD-L1) & $\mathbf{1 . 6 0 7}$ & $\mathbf{1 . 0 2 7 - 2 . 5 1 3}$ & $\mathbf{0 . 0 3 8}$ & 2.091 & $0.871-5.024$ & 0.099 & 1.791 & $0.816-3.931$ & 0.146 \\
IDO-1 & $\mathbf{1 . 4 6 5}$ & $\mathbf{1 . 0 6 9 - 2 . 0 0 9}$ & $\mathbf{0 . 0 1 8}$ & $\mathbf{2 . 2 3 4}$ & $\mathbf{1 . 3 2 7 - 3 . 7 6 2}$ & $\mathbf{0 . 0 0 3}$ & $\mathbf{2 . 1 0 7}$ & $\mathbf{1 . 3 1 1}-3.388$ & $\mathbf{0 . 0 0 2}$ \\
CD68 & 1.256 & $0.768-2.054$ & 0.364 & 2.319 & $0.923-5.826$ & 0.074 & $\mathbf{2 . 4 0 5}$ & $\mathbf{1 . 0 5 6 - 5 . 4 7 5}$ & $\mathbf{0 . 0 3 7}$ \\
CD163 & 0.895 & $0.691-1.161$ & 0.404 & 1.217 & $0.771-1.923$ & 0.399 & 1.364 & $0.908-2.050$ & 0.135 \\
\hline
\end{tabular}

HR, hazard ratio; CI, confidence interval; FFTF, freedom from treatment failure; DSS, disease-specific survival; OS, overall survival. Boldface font indicates statistical significance $(p<0.05)$.

\subsection{High Number of PD-L1+ and IDO-1+ Cells Translates to Inferior Outcome}

To further examine the expression of PD-L1 and IDO-1 proteins in the tumor tissue, and particularly in TAMs, we profiled the cellular immunophenotypes with antibody-based mIHC. As a general marker of TAMs, we used CD68, whereas subpopulations of TAMs were defined by the presence or absence of CD163, PD-L1 and IDO-1 (Figure 1a,b). There was a good correlation between the gene expression and the mIHC data. The proportions of $\mathrm{CD}^{+} 8^{+}$cells, $\mathrm{CD} 163^{+}$cells, IDO- $1^{+}$cells, and PD-L1 ${ }^{+}$cells in the mIHC analysis correlated with the gene expression of CD68 $(\rho=0.681, p<0.001), C D 163(\rho=0.764$, $p<0.001), C D 274(\rho=0.688, p<0.001)$ and IDO-1 $(\rho=0.762, p<0.001)$, respectively (Figure S1b). In addition, in the mIHC analysis the quantities of PD-L1 $1^{+}$and IDO- $1^{+}$cells correlated with $\mathrm{CD} 68^{+}$ cells (PD-L1 ${ }^{+}, \rho=0.691, p<0.001$; IDO- $1^{+}, \rho=0.196, p=0.025$ ) and CD163 ${ }^{+}$cells (PD-L1 ${ }^{+}, \rho=0.374$, $p<0.001$; IDO- $\left.1^{+}, \rho=0.206, p=0.019\right)$. Furthermore, $\mathrm{CD}^{+} 8^{+}$and $\mathrm{CD} 163^{+}$cells correlated with each other $(\rho=0.626, p<0.001)$ (Figure S1c). Finally, IDO- $1^{+}$and PD-L1 ${ }^{+}$macrophages correlated with interferon $\gamma$ gene expression (Table S1). The proportions of distinct cell subsets in the cHL tissue are shown in Figure 1c. CD $68^{+}$and $\mathrm{CD} 163^{+}$TAM contents, as well as the PD-L1 ${ }^{+}$and IDO- ${ }^{+}$cells contents from all cells, showed great variation between the samples (CD68 ${ }^{+}$TAMs, median 20\%, range $7.0-50 \%$; CD $163^{+}$TAMs, median $8.6 \%$, range $0.2-50 \%$; PD-L1 $^{+}$cells, median $14 \%$, range $0.1-68 \%$ and IDO- $1^{+}$cells, median $3.7 \%$, range $0-63 \%$; Figure 1c). Consistent with the gene expression data, high PD-L1 $1^{+}$and IDO- $1^{+}$cell contents translated to poor FFTF, DSS and OS when analyzed as continuous variables, whereas the proportions of either $\mathrm{CD}^{+} 8^{+}, \mathrm{CD} 163^{+}$, or $\mathrm{CD} 68^{+} \mathrm{CD} 163^{-}$TAMs of all cells did not correlate with survival (Table 3). 
Table 3. Cox regression analysis as continuous variables at univariate level showing association of cell immunophenotypes with FFTF, DSS and OS.

\begin{tabular}{|c|c|c|c|c|c|c|c|c|c|}
\hline \multirow{2}{*}{$\begin{array}{l}\text { Cell Immunophenotype (Proportion from } \\
\text { All Cells) }\end{array}$} & \multicolumn{3}{|c|}{ FFTF } & \multicolumn{3}{|c|}{ DSS } & \multicolumn{3}{|c|}{ OS } \\
\hline & HR & $95 \% \mathrm{CI}$ & $p$ & HR & $95 \%$ CI & $p$ & HR & $95 \%$ CI & $p$ \\
\hline PD-L1 ${ }^{+}$ & 1.027 & $1.003-1.051$ & 0.025 & 1.069 & $1.018-1.123$ & 0.007 & 1.054 & $1.012-1.098$ & 0.011 \\
\hline IDO- $1^{+}$ & 1.048 & $1.020-1.076$ & 0.001 & 1.082 & $1.042-1.123$ & $<0.001$ & 1.074 & $1.039-1.111$ & $<0.001$ \\
\hline $\mathrm{CD}^{+} 0^{+}$ & 1.059 & $0.967-1.160$ & 0.217 & 1.147 & $1.001-1.315$ & 0.049 & 1.087 & $0.949-1.245$ & 0.227 \\
\hline $\mathrm{CD}^{+} 8^{+}$ & 1.012 & $0.970-1.055$ & 0.594 & 1.045 & $0.956-1.143$ & 0.331 & 1.061 & $0.989-1.139$ & 0.098 \\
\hline $\mathrm{CD}_{163^{+}}$ & 1.009 & $0.981-1.037$ & 0.541 & 1.035 & $0.981-1.091$ & 0.206 & 1.041 & $0.997-1.086$ & 0.066 \\
\hline $\mathrm{CD}^{+} 8^{+} \mathrm{CD} 163^{-}$ & 1.022 & $0.959-1.088$ & 0.506 & 1.009 & $0.877-1.161$ & 0.899 & 0.994 & $0.883-1.118$ & 0.914 \\
\hline $\mathrm{PD}^{\mathrm{L}} 1^{+} \mathrm{CD} 68^{+}$ & 1.042 & $1.002-1.084$ & 0.040 & 1.109 & $1.031-1.194$ & 0.006 & 1.093 & $1.026-1.164$ & 0.006 \\
\hline $\mathrm{PD} \mathrm{L1}^{+} \mathrm{CD} 163^{+}$ & 1.029 & $0.993-1.066$ & 0.114 & 1.099 & $1.030-1.172$ & 0.004 & 1.088 & $1.031-1.148$ & 0.002 \\
\hline IDO- $1^{+}$CD $68^{+}$ & 1.107 & $1.021-1.201$ & 0.014 & 1.235 & $1.107-1.378$ & $<0.001$ & 1.221 & $1.105-1.348$ & $<0.001$ \\
\hline $\mathrm{IDO}^{-} 1^{+} \mathrm{CD} 163^{+}$ & 1.181 & $1.070-1.304$ & 0.001 & 1.319 & $1.163-1.495$ & $<0.001$ & 1.290 & $1.151-1.447$ & $<0.001$ \\
\hline $\mathrm{PD}^{-\mathrm{L}^{-}{ }^{-} \mathrm{CD} 68^{+}}$ & 0.980 & $0.914-1.051$ & 0.576 & 0.918 & $0.763-1.104$ & 0.363 & 0.987 & $0.872-1.117$ & 0.837 \\
\hline $\mathrm{PD}^{-\mathrm{L1}^{-} \mathrm{CD} 163^{+}}$ & 0.991 & $0.947-1.037$ & 0.703 & 0.962 & $0.848-1.091$ & 0.543 & 1.001 & $0.940-1.087$ & 0.770 \\
\hline $\mathrm{IDO}^{-1^{-} \mathrm{CD} 68^{+}}$ & 0.976 & $0.928-1.025$ & 0.330 & 0.884 & $0.755-1.036$ & 0.129 & 0.982 & $0.898-1.074$ & 0.690 \\
\hline IDO- $1^{-} \mathrm{CD} 163^{+}$ & 0.993 & $0.956-1.032$ & 0.732 & 0.987 & $0.902-1.080$ & 0.775 & 1.015 & $0.960-1.074$ & 0.595 \\
\hline $\mathrm{PD}^{\mathrm{L} 1}{ }^{+} \mathrm{CD} 30^{+}$ & 1.063 & $0.922-1.225$ & 0.402 & 1.192 & $0.928-1.532$ & 0.169 & 1.093 & $0.854-1.401$ & 0.480 \\
\hline $\begin{array}{l}\text { Cell immunophenotype (proportion from } \\
\text { specific cell subtype) }\end{array}$ & HR & $95 \% \mathrm{CI}$ & $p$ & HR & $95 \% \mathrm{CI}$ & $p$ & HR & $95 \% \mathrm{CI}$ & $p$ \\
\hline $\mathrm{PD}^{-\mathrm{L}^{+}{ }^{+} \mathrm{CD} 68^{+} / \mathrm{CD} 8^{+}}$ & 1.021 & $1.003-1.039$ & 0.024 & 1.047 & $1.005-1.090$ & 0.027 & 1.034 & $1.001-1.068$ & 0.042 \\
\hline $\mathrm{PD} \mathrm{L1}^{+} \mathrm{CD} 163^{+} / \mathrm{CD} 163^{+}$ & 1.020 & $1.006-1.035$ & 0.005 & 1.038 & $1.005-1.072$ & 0.022 & 1.028 & $1.002-1.054$ & 0.036 \\
\hline 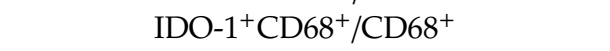 & 1.032 & $1.009-1.057$ & 0.007 & 1.066 & $1.031-1.102$ & $<0.001$ & 1.059 & $1.028-1.091$ & $<0.001$ \\
\hline 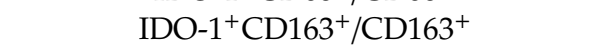 & 1.040 & $1.015-1.066$ & 0.002 & 1.062 & $1.030-1.094$ & $<0.001$ & 1.057 & $1.028-1.087$ & $<0.001$ \\
\hline $\mathrm{PD}^{\mathrm{L}} 1^{+} \mathrm{CD} 30^{+} / \mathrm{CD} 30^{+}$ & 1.008 & $0.992-1.024$ & 0.323 & 1.016 & $0.981-1.053$ & 0.369 & 1.008 & $0.981-1.036$ & 0.555 \\
\hline
\end{tabular}

HR, hazard ratio; CI, confidence interval; FFTF, freedom from treatment failure; DSS, disease-specific survival; OS, overall survival. Boldface font indicates statistical significance ( $p<0.05)$. 


\subsection{High Proportions of $\mathrm{PD}-\mathrm{L} 1^{+}$and IDO-1 ${ }^{+}$TAMs Translate to Inferior Outcome}

We further observed that a significant amount of PD-L1 (median 45\%, range 15-85\%) and IDO-1 (median 22\%, range 0-62\%) was expressed in macrophages (Figure 1c). Of the CD68 ${ }^{+}$and CD163 ${ }^{+}$ M2-like TAMs, 32\% (range 0.2-89\%) and 22\% (range 0.1-94\%) expressed PD-L1, whereas fewer CD68 ${ }^{+}$ (median 5.5\%, range 0-73\%) and CD163 ${ }^{+}$TAMs (median 1.4\%, range 0-74\%) were characterized as IDO- $1^{+}$(Figure 1d). Both high proportions of PD-L1 ${ }^{+}$or IDO- $1^{+}$macrophages from all cells, and high proportions of PD-L1 ${ }^{+}$or IDO- $1^{+}$macrophages from all macrophages (high PD-L1 ${ }^{+} \mathrm{CD} 68^{+} / \mathrm{CD}^{+} 8^{+}$, $\mathrm{PD}-\mathrm{L}^{+}{ }^{+} \mathrm{CD} 163^{+} / \mathrm{CD} 63^{+}, \mathrm{IDO}-1^{+} \mathrm{CD} 68^{+} / \mathrm{CD} 68^{+}$and $\mathrm{IDO}-1^{+} \mathrm{CD} 163^{+} / \mathrm{CD} 63^{+}$cell ratio) translated to inferior survival when analyzed as continuous variables (Table 3). In contrast, neither the ratio of PD-L1 ${ }^{-}$nor IDO-1 ${ }^{-}$macrophages from all cells were associated with an outcome. Furthermore, based on the proportions of PD-L1 ${ }^{+}$and IDO- $1^{+}$macrophages from all macrophages, patients were divided into two subgroups with low and high PD-L1 ${ }^{+} \mathrm{CD} 68^{+} / \mathrm{CD} 68^{+}$and $\mathrm{IDO}-1^{+} \mathrm{CD} 68^{+} / \mathrm{CD} 68^{+}$ratios (Figure 2). According to Kaplan-Meier estimates, the 5-year FFTF rates were significantly worse for the patients with high ratio of PD-L1 ${ }^{+}$TAMs ( $59 \%$ vs. $\left.85 \%, p=0.002\right)$ and IDO- $1^{+}$TAMs $(71 \%$ vs. $89 \%, p=0.003$ ) from all macrophages in comparison to patients with low ratios. When the distribution of the baseline characteristics was compared between the high and low subgroups, no significant differences in gender, age and IPS were observed (Table 4). However, patients with high PD-L1 ${ }^{+} \mathrm{CD} 68^{+} / \mathrm{CD} 68^{+}$or IDO- $1^{+} \mathrm{CD} 68^{+} / \mathrm{CD} 68^{+}$proportions more frequently had other $\mathrm{cHL}$ subtypes than NS, advanced than limited stage disease and were EBV positive.
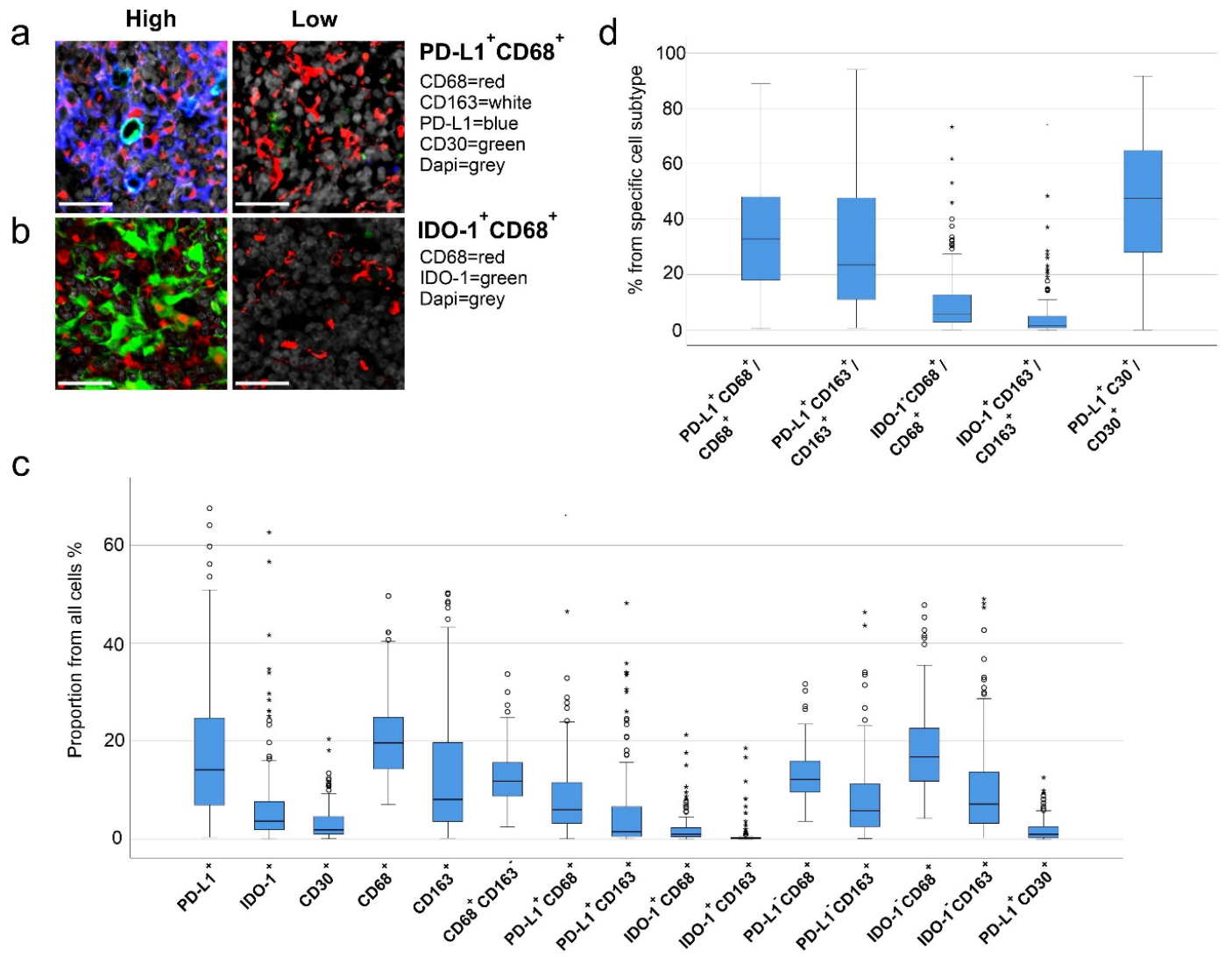

Figure 1. Immunophenotypes of different cells. Representative images of (a) PD-L1 ${ }^{+} \mathrm{CD} 68^{+}$and (b) IDO- $1^{+} \mathrm{CD} 68^{+}$high and low cell proportions from all cells (scale bars $30 \mu \mathrm{m}$ ). (c) Boxplots representing proportions of different cell types from all cells. (d) Boxplots representing proportions of PD-L1 ${ }^{+}$ and IDO- $1^{+}$tumor-associated macrophages (TAMs) from all TAMs and PD-L1 ${ }^{+} \mathrm{CD} 30^{+}$cells from all CD $30^{+}$cells. 
a

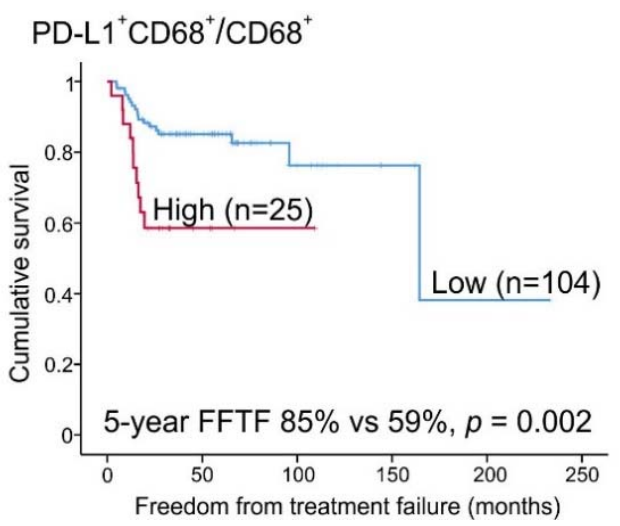

b

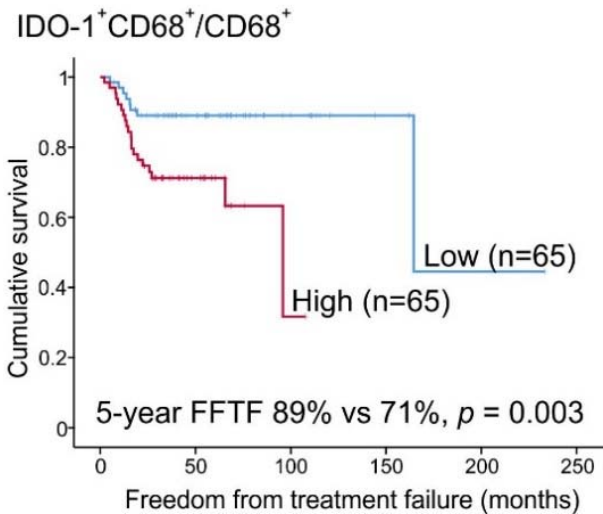

Figure 2. Association of the macrophage immunophenotypes with FFTF. Kaplan-Meier estimates for FFTF according to (a) $\mathrm{PD}-\mathrm{L} 1{ }^{+} \mathrm{CD} 68^{+} / \mathrm{CD} 68^{+}$cell ratio (cut-off highest fifth, $50 \%$ ) and (b) IDO- $1^{+} \mathrm{CD} 68^{+} / \mathrm{CD}^{+} 8^{+}$cell ratio (cut-off median, 5.5\%) dividing the patients into high and low cell ratio subgroups.

Table 4. Distribution of baseline characteristics between high and low cell ratio of PD-L1 $1^{+} \mathrm{CD} 68^{+} / \mathrm{CD} 68^{+}$ and IDO- $1^{+} \mathrm{CD} 68^{+} / \mathrm{CD} 68^{+}$.

\begin{tabular}{|c|c|c|c|c|c|c|}
\hline \multirow{2}{*}{ Characteristic } & \multicolumn{3}{|c|}{$\mathrm{PD} \mathrm{L1}^{+}{ }^{+} \mathrm{CD}{ }^{+} / \mathrm{CD} 8^{+}$} & \multicolumn{3}{|c|}{$\mathrm{IDO}-1^{+} \mathrm{CD} 8^{+} / \mathrm{CD} 8^{+}$} \\
\hline & Low & High & $p$ & Low & High & $p$ \\
\hline $\begin{array}{c}\text { Number of Patients (\%) } \\
\text { Sex }\end{array}$ & \multicolumn{4}{|c|}{ Sex } & 65 & \\
\hline Male & $45(43)$ & $13(52)$ & 0.431 & $29(45)$ & $30(46)$ & 0.86 \\
\hline Female & $59(57)$ & $12(48)$ & & $36(55)$ & $35(54)$ & \\
\hline Age (years) & & & 0.837 & & & \\
\hline$<60$ & $93(89)$ & $22(88)$ & & $60(92)$ & $56(86)$ & 0.258 \\
\hline$\geq 60$ & $11(11)$ & $3(12)$ & & $5(8)$ & $9(14)$ & \\
\hline \multicolumn{7}{|l|}{ Subtype } \\
\hline NS & $86(83)$ & $16(64)$ & 0.039 & $57(88)$ & $45(69)$ & 0.01 \\
\hline Other * & $8(17)$ & $9(36)$ & & $8(12)$ & $20(31)$ & \\
\hline \multicolumn{7}{|l|}{ Stage } \\
\hline I-IIA & $49(48)$ & $6(24)$ & 0.033 & $34(53)$ & $22(34)$ & 0.027 \\
\hline IIB-IV & $54(52)$ & $19(76)$ & & $30(47)$ & $43(66)$ & \\
\hline \multicolumn{7}{|l|}{ EBV status } \\
\hline Negative & $75(76.5)$ & $13(54)$ & 0.029 & $48(81)$ & $23(64)$ & 0.032 \\
\hline $\begin{array}{l}\text { Positive } \\
\text { IPS }\end{array}$ & $23(23.5)$ & $11(46)$ & & $11(19)$ & $41(36)$ & \\
\hline $0-3$ & $66(92)$ & $20(95)$ & 0.585 & $42(93)$ & $44(92)$ & 0.761 \\
\hline $4-7$ & $6(8)$ & $1(5)$ & & $3(7)$ & $4(8)$ & \\
\hline
\end{tabular}

* Other: Mixed cellularity (MC) + other/unclassified cHL. NS, nodular sclerosis; EBV, Epstein-Barr virus; IPS, International Prognostic Score. Boldface font indicates statistical significance $(p<0.05)$.

\subsection{PD-L1 Expression in HRS Cells}

We also examined association of CD $30^{+}$HRS cells with PD-L1 positivity. As expected, the median proportion of $\mathrm{CD} 30^{+} \mathrm{HRS}$ cells from the whole tumor cellularity was low (median $1.8 \%$, range 0.06-20\%), and about half of CD30 ${ }^{+}$HRS cells were PD-L1 ${ }^{+}$(median 47\%, range 0-92\%) (Figure 1c). The proportion of PD-L1 ${ }^{+}$HRS cells $\left(\mathrm{PD}-\mathrm{L}^{+}{ }^{+} \mathrm{CD} 30^{+} / \mathrm{CD} 30^{+}\right)$correlated with the proportion of PD-L1 ${ }^{+}$ macrophages (PD-L1 ${ }^{+} \mathrm{CD} 68^{+} / \mathrm{CD}^{+} 8^{+} ; \rho=0.479, p<0.001$ ). While high $\mathrm{CD} 30^{+}$cell content in the tumor tissue translated to inferior DSS, neither the proportion of PD-L1 $1^{+} \mathrm{CD} 30^{+}$cells from all cells, nor the $\mathrm{PD}-\mathrm{L} 1^{+} \mathrm{CD} 30^{+} / \mathrm{CD} 30^{+}$cell ratio correlated with survival (Table 3 ). 


\subsection{Prognostic Impact of $\mathrm{PD}-\mathrm{L} 1^{+}$and IDO-1+ TAM Proportions}

To further assess the prognostic value of high and low PD-L1 ${ }^{+}$and IDO-1 ${ }^{+}$TAM ratios with clinical risk factors, Cox regression analyses were performed with categorical variables (Table 5). Besides subgroups of patients with high PD-L1 ${ }^{+} \mathrm{CD} 68^{+} / \mathrm{CD} 68^{+}$and IDO- $1^{+} \mathrm{CD} 68^{+} / \mathrm{CD} 68^{+}$cell ratios, age ( $\geq 60$ years) and stage (IIB-IV) had adverse prognostic impact on FFTF in our mIHC cohort. High PD-L1 ${ }^{+} \mathrm{CD} 68^{+} / \mathrm{CD} 8^{+}$cell ratio and high age ( $\geq 60$ years) also had adverse prognostic impact on DSS and OS, whereas EBV positivity and high IPS (4-7) were associated only with poor OS. Gender or cHL subtype did not have any association with survival. High $\mathrm{PD}-\mathrm{L} 1^{+} \mathrm{CD} 68^{+} / \mathrm{CD} 68^{+}$ratio remained as an adverse prognostic factor for FFTF, DSS and OS when adjusted for cHL subtype, and also for FFTF and DSS when adjusted for stage or EBV status, whereas the association with OS remained significant only in the EBV negative cases (EBV-, HR $=7.687,(95 \%$ CI 1.067-55.362), $p=0.043$; EBV+, $\mathrm{HR}=1.860(95 \%$ CI 0.306-11.296), $p=0.500)$ and was more evident in the patients with advanced than limited stage (Stage IIB-IV, HR = 3.824 (95\% CI 0.935-15.636), $p=0.062$; stage I-IIA, HR $=0.043$ (95\% CI $0.000-2.971 \times 1011), p=0.835)$. Furthermore, when IDO- $1^{+} \mathrm{CD} 68^{+} / \mathrm{CD} 68^{+}$content was adjusted for stage, cHL subtype or EBV status, a high ratio remained as an adverse prognostic factor for FFTF. In multivariate analysis, both $\mathrm{PD}-\mathrm{L} 1^{+} \mathrm{CD} 68^{+} / \mathrm{CD} 68^{+}$ratio and $\mathrm{IDO}-1^{+} \mathrm{CD} 68^{+} / \mathrm{CD} 68^{+}$ratio predicted FFTF independently of age and stage (Table 6). 
Table 5. Cox regression analysis as categorical variables at univariate level showing association of $\mathrm{PD}-\mathrm{L} 1^{+} \mathrm{CD} 68^{+} / \mathrm{CD} 68^{+}$cell ratio, IDO- $1^{+} \mathrm{CD} 68^{+} / \mathrm{CD} 68^{+}$cell ratio and clinical characteristics of mIHC cohort with FFTF, DSS and OS

\begin{tabular}{|c|c|c|c|c|c|c|c|c|c|}
\hline \multirow{2}{*}{ Characteristic } & \multicolumn{3}{|c|}{ FFTF } & \multicolumn{3}{|c|}{ DSS } & \multicolumn{3}{|c|}{ OS } \\
\hline & HR & $95 \%$ CI & $p$ & HR & $95 \% \mathrm{CI}$ & $p$ & HR & $95 \% \mathrm{CI}$ & $p$ \\
\hline $\mathrm{PD}^{-\mathrm{L}^{+} \mathrm{CD} 68^{+} / \mathrm{CD} 8^{+} \text {(high) }}$ & 3.222 & $1.46-7.09$ & 0.004 & 11.958 & $2.15-66.63$ & 0.005 & 4.646 & $1.23-17.54$ & 0.023 \\
\hline $\mathrm{IDO}^{+} \mathrm{C}^{+} \mathrm{CD}^{+} 8^{+} / \mathrm{CD} 8^{+}$(high) & 3.537 & $1.47-8.50$ & 0.005 & 6.050 & $0.70-52.21$ & 0.102 & 4.237 & $0.88-20.52$ & 0.073 \\
\hline 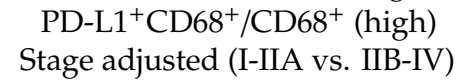 & 2.525 & $1.12-5.68$ & 0.025 & 8.243 & $1.46-46.64$ & 0.017 & 3.348 & $0.87-12.86$ & 0.078 \\
\hline $\begin{array}{l}\text { IDO- }^{+}{ }^{+} \mathrm{CD} 8^{+} / \mathrm{CD} 8^{+} \text {(high) } \\
\text { Stage adjusted (I-IIA vs. IIB-IV) }\end{array}$ & 2.586 & $1.08-6.17$ & 0.032 & 4.154 & $0.48-35.77$ & 0.195 & 3.301 & $0.67-16.38$ & 0.144 \\
\hline $\begin{array}{l}\mathrm{PD}_{\mathrm{L} 1}{ }^{+} \mathrm{CD} 68^{+} / \mathrm{CD} 68^{+} \text {(high) } \\
\text { Subtype adjusted (NS vs. others) }\end{array}$ & 3.455 & $1.54-7.75$ & 0.003 & 11.123 & $1.93-64.09$ & 0.007 & 4.202 & $1.08-16.36$ & 0.038 \\
\hline $\begin{array}{c}\text { IDO- }^{+}{ }^{+} \text {CD } 68^{+} / \mathrm{CD} 8^{+} \text {(high) } \\
\text { Subtype adjusted (NS vs. others) }\end{array}$ & 3.419 & $1.41-8.32$ & 0.007 & 5.711 & $0.65-51.57$ & 0.117 & 3.957 & $0.79-19.86$ & 0.095 \\
\hline $\begin{array}{l}\text { PD-L } 1^{+} \text {CD } 68^{+} / \mathrm{CD} 68^{+} \text {(high) } \\
\text { EBV status adjusted (neg vs. pos) }\end{array}$ & 3.715 & $1.64-8.41$ & 0.002 & 11.071 & $1.91-64.06$ & 0.007 & 3.450 & $0.88-13.50$ & 0.075 \\
\hline $\begin{array}{l}\text { IDO- } 1^{+} \mathrm{CD} 68^{+} / \mathrm{CD}^{6} 8^{+} \text {(high) } \\
\text { EBV status adjusted (neg vs. pos) }\end{array}$ & 3.937 & $1.54-10.06$ & 0.004 & 5.390 & $0.61-47.52$ & 0.129 & 3.237 & $0.65-16.03$ & 0.150 \\
\hline Age $(\geq 60 y)$ & 3.799 & $1.60-9.00$ & 0.002 & 12.708 & $2.46-65.55$ & 0.002 & 16.516 & $4.30-63.37$ & $<0.001$ \\
\hline Stage (IIB-IV) & 7.791 & $2.35-25.82$ & 0.001 & 55.058 & $0.07-41007.16$ & 0.235 & 6.631 & $0.83-53.06$ & 0.075 \\
\hline Female & 0.676 & $0.32-1.42$ & 0.303 & 0.746 & $0.15-3.71$ & 0.721 & 0.596 & $0.16-2.23$ & 0.442 \\
\hline EBV-status (positive) & 0.811 & $0.33-2.02$ & 0.653 & 1.608 & $0.29-8.84$ & 0.585 & 4.100 & $1.09-15.38$ & 0.036 \\
\hline IPS (4-7) & 1.157 & $0.27-4.95$ & 0.854 & 4.603 & $0.48-44.65$ & 0.188 & 9.725 & $1.61-58.77$ & 0.013 \\
\hline Other cHL subtype than NS & 1.106 & $0.44-2.76$ & 0.829 & 2.527 & $0.45-14.35$ & 0.295 & 2.582 & $0.63-10.61$ & 0.188 \\
\hline
\end{tabular}

IPS, International Prognostic Score; EBV, Epstein-Barr virus; NS, nodular sclerosis; HR, hazard ratio; CI, confidence interval; FFTF, freedom from treatment failure; DSS, disease-specific survival; OS, overall survival. Boldface font indicates statistical significance $(p<0.05)$. 
Table 6. Cox regression analysis at multivariate level showing independent association of $\mathrm{PD}-\mathrm{L} 1^{+} \mathrm{CD} 68^{+} / \mathrm{CD} 68^{+}$or IDO- $1^{+} \mathrm{CD} 68^{+} / \mathrm{CD} 68^{+}$cell ratio, stage and age with FFTF.

\begin{tabular}{|c|c|c|c|}
\hline Risk Factor & HR & $95 \% \mathrm{CI}$ & $p$ \\
\hline $\mathrm{PD}^{2} 1^{+}{ }^{+}{ }^{2} 8^{+} / \mathrm{CD}^{+} 8^{+}$(high) & 2.625 & $1.173-5.876$ & 0.019 \\
\hline Stage (IIB-IV) & 5.834 & $1.720-19.786$ & 0.005 \\
\hline Age ( $\geq 60$ years) & 2.631 & $1.095-6.319$ & 0.031 \\
\hline $\mathrm{IDO}^{+}{ }^{+} \mathrm{CD}^{+} 8^{+} / \mathrm{CD}^{+} 8^{+}$(high) & 2.480 & $1.034-5.947$ & 0.042 \\
\hline Stage (IIB-IV) & 5.799 & $1.705-19.717$ & 0.005 \\
\hline Age ( $\geq 60$ years $)$ & 2.221 & $0.921-5.356$ & 0.076 \\
\hline
\end{tabular}

$\mathrm{HR}$, hazard ratio; $\mathrm{CI}$, confidence interval; FFTF, freedom from treatment failure. Boldface font indicates statistical significance $(p<0.05)$.

\section{Discussion}

The aim of our study was to quantify and characterize immunophenotypes of TAMs and investigate whether PD-L1 ${ }^{+}$and IDO-1 ${ }^{+}$TAMs have prognostic value in primary cHL patients treated with standard chemo- and radiotherapy. First, we observed that high gene expression levels of PD-L1 and IDO-1 were associated with poor survival. A similar correlation was observed at the protein level. Given the accentuated expression of PD-L1 and IDO-1 in TAMs, high proportions of PD-L1 ${ }^{+}$TAMs and IDO- $1^{+}$TAMs also translated to inferior outcome. These survival associations were seen within both overall $\mathrm{CD} 68^{+}$TAMs and in $\mathrm{CD} 163^{+}$putative M2-like TAMs, suggesting subtype-independent association, although M2-like alternatively activated macrophages have been considered to be pro-tumoral [3] and promote immunosuppression [22]. On the contrary, in our study population, neither the proportion of macrophages $\left(\mathrm{CD} 8^{+}\right.$or $\left.\mathrm{CD}_{163}{ }^{+}\right)$, nor the $\mathrm{PD}-\mathrm{L1}^{-}$or IDO- $1^{-}$ TAMs translated to survival. These results indicate that only distinct TAM immunophenotypes mediate significant adverse impact on survival.

Our data emphasize the diversity of the TME, since the proportions of different cell types varied significantly between the patients, as did the cell ratios of PD-L1 ${ }^{+}$and IDO- $1^{+}$macrophages from all macrophages. Furthermore, despite the finding that only a very small proportion of CD163 ${ }^{+}$TAMs were IDO- $1^{+}$(median $1.4 \%$ ), these few cells had a notably adverse impact on the treatment outcome, highlighting the importance of the subgroup of macrophages as immunomodulators in the TME. Furthermore, considering the variation of checkpoint molecule expression on TAMs, our findings may potentially provide explanation for the opposite results in previous studies, which have investigated the prognostic impact of $\mathrm{CD}^{+} 8^{+}$and/or $\mathrm{CD}_{163^{+}}$macrophages [15].

Although the overall proportion of PD-L1 ${ }^{+}$cells was associated with inferior outcome, neither the proportion of $\mathrm{PD}-\mathrm{L} 1^{+} \mathrm{CD} 30^{+}$cells nor the ratio of $\mathrm{PD}-\mathrm{L} 1^{+} \mathrm{CD} 30^{+} / \mathrm{CD} 30^{+}$cells translated to inferior survival. This finding is important by demonstrating that the adverse prognostic impact of PD-L1 expression is TME-dependent, and, particularly, TAM-dependent. Interestingly, two previous studies also showed that neither the expression of PD-L1 nor PD-L2 on HRS cells is associated with outcome $[10,23]$. Unfortunately, we could not address the same question with IDO-1, because our mIHC antibody panel design did not allow analysis of IDO- 1 and CD30 expression simultaneously. However, it has been observed previously that IDO-1 is not expressed in HRS cells [11]. Together with previous results, our data imply that prognostic impact of IDO-1 expression is also derived from the TME and TAMs. Whether IDO-1 and PD-L1 are expressed on the same macrophages and whether those macrophages have even more remarkable association with outcome remains unanswered in the framework of this study. However, our results propose that PD-L1 ${ }^{+}$TAMs are more abundant than IDO- $1^{+}$TAMs. The overall proportion of PD-L1 ${ }^{+}$cells is also higher than IDO- $1^{+}$cells in the tumor tissue, indicating variation between the expression of these two molecules on macrophages.

We have previously demonstrated the importance of PD-L1 ${ }^{+}$TAMs on survival in patients with primary testicular lymphoma [24]. To our knowledge, however, this is the first study in cHL to show that high proportions of IDO-1 and PD-L1 expressing TAMs from all TAMs predict worse 
FFTF independently from clinical risk factors. This was evident regardless of the EBV status, and in contrast to previous studies showing that survival association of TAMs is limited to EBV negative cases $[16,25]$. Furthermore, in this study, high ratios of $\mathrm{PD}-\mathrm{L} 1^{+} \mathrm{CD} 68^{+} / \mathrm{CD} 8^{+}$and IDO- $1^{+} \mathrm{CD} 68^{+} / \mathrm{CD} 68^{+}$ were associated with EBV positivity, which is in line with previous studies showing higher expression of macrophages [13,26], PD-L1 [4] and IDO [11] in EBV positive rather than negative cases. The correlation of PD-L1 ${ }^{+}$and IDO- $1^{+}$TAMs with interferon $\gamma$ gene expression in turn suggests an interaction between TAMs and cytotoxic T lymphocytes.

The mechanism for immune evasion via IDO- $1^{+}$and $\mathrm{PD}-\mathrm{L}^{+}$macrophages remains unclear, and further studies are needed to resolve this question. However, PD-L1 ${ }^{+}$TAMs have been shown to be in contact both with PD- $1^{+} \mathrm{CD} 4^{+}$T-cells and PD- ${ }^{+} \mathrm{CD}{ }^{+}$T-cells in the close vicinity of HRS cells [7], possibly implying that TAMs interact with PD-1 ${ }^{+}$T-cells in promoting immunosuppression. Interestingly, suppression of PD- ${ }^{+}$natural killer $(\mathrm{NK})$ cells has also been recently shown to occur via PD-L1 expressing CD163 ${ }^{+}$TAMs, and more prominently in $\mathrm{cHL}$ than in diffuse large cell lymphoma (DLBCL) [27].

PD-1 blockade with monoclonal antibodies has demonstrated promising response rates (65-87\%) and long-term remissions in a subgroup of poor prognosis patients with relapsed and refractory cHL [28-31]. Currently, there are several ongoing clinical trials investigating PD-1 blockade alone as a first-line treatment or in combination with chemotherapy or brentuximab vedotin [32-34]. Interestingly, it has previously been suggested that therapies affecting the PD-1 pathway may also function through macrophages [35]. IDO-1 inhibitors are also under investigation in clinical trials alone and in combination with other therapies in different advanced malignancies, including lymphomas [8,36]. Our results suggest that IDO- $1^{+}$and PD-L1 ${ }^{+}$TAMs could be potential targets for novel immunotherapies. They might also be useful biomarkers to stratify treatments in cHL. The patients with high proportions of IDO- $1^{+}$or PD-L1 ${ }^{+}$macrophages at the time of diagnosis may define subgroups that particularly benefit from PD-1 and/or IDO-1 blockade.

In this study we have demonstrated that high proportions of PD-L1 ${ }^{+}$and IDO- ${ }^{+}$TAMs are both associated with unfavorable outcomes in cHL patients treated with standard chemotherapy. The results should be confirmed prospectively in an independent cohort of cHL patients. Nevertheless, they provide rationale for studying PD-1 and IDO-1 inhibitors in combination with standard chemotherapy for patients with high PD-L1 ${ }^{+}$and IDO- $1^{+}$TAM content in their tumor tissue.

\section{Materials and Methods}

\subsection{Patients and Samples}

The study material included clinical data and diagnostic formalin-fixed paraffin-embedded (FFPE) tumor tissue samples from the patients with primary cHL. All patients were diagnosed between the years 1993-2012 and were treated or followed in Helsinki University Hospital. Patients and corresponding clinical data were retrospectively extracted from electronic and/or paper-based medical records. Gene expression data from 88 patients enriched in elderly and relapsed/refractory (R/R) cases were used for screening. The main study cohort consisted of 130 patients, who were selected based on the availability of representative tumor tissue for tissue microarray (TMA) and which was named as "mIHC cohort". Seventy-eight patients were overlapping between the gene expression dataset and the mIHC cohort.

Detailed description of staging procedures, response evaluation and treatment is provided in the Supplementary Materials.

Patient data were handled according to Good Scientific Practice (GSP) Guidelines. The study was approved by the Ethics Committee in Helsinki University Hospital (Finland; HUS/1230/2017), and by the Finnish National Authority for Medicolegal Affairs (9505/06.01.03.01/2013), which waived the requirement to obtain informed consent. 


\subsection{Gene Expression Analysis}

Gene expression levels of macrophage markers CD68 and CD163, INFG (gene encoding interferon $\gamma$ ), and immunosuppressive molecules CD274 (gene encoding PD-L1) and IDO-1 were measured from 88 samples using digital gene expression analysis with NanoString nCounter (NanoString Technologies, Seattle, WA, USA) [37].

\subsection{Multiplex Immunohistochemistry}

TMA was constructed from one to six replicate spots of the same FFPE tumor tissue. Core selection on the TMA was based on the evaluation of a hematopathologist. TMA sections were stained with panels of primary antibodies for CD68, CD163, PD-L1, IDO-1 and CD30. CD68 was used as universal macrophage marker, CD163 as marker for M2-polarized macrophages, CD30 as a marker to recognize HRS-cells, and PD-L1 and IDO-1 for immunosuppression. The quantities of different immunophenotypes were counted as proportion from all cells or from specific cells on the whole TMA spot. The mean value of the cell proportions from the same tissue samples replicate spots were used. The mIHC analysis was performed digitally using the open-source platform CellProfiler [38]. A description of mIHC method is given in the Supplementary Materials. Antibodies for CD68, CD163 and IDO- 1 were included in two panels, and in the analysis the mean values of the cell proportions from these two separate panels were used. The correlations were high between the panels for cell proportions of CD68 ${ }^{+}(\rho=0.736, p<0.001), \mathrm{CD} 63^{+}(\rho=0.960, p<0.001)$ and IDO- $1^{+}$cells $(\rho=0.939$, $p<0.001)$, respectively, emphasizing the reliability and repeatability of the method.

\subsection{Determination of Epstein-Barr Virus Status}

EBV status was determined as either negative or positive using Epstein-Barr virus encoded RNA (EBER) in situ hybridization (ISH) for the TMAs. Cases with positive nuclear staining of HRS-cells were qualified as EBV positive.

\subsection{Statistical Analysis}

FFTF was defined as the time between the date of the diagnosis and disease progression, including progression during primary therapy and later relapses. OS was defined as time between the date of the diagnosis and death from any cause, and DSS as the time between the date of the diagnosis and death due to cHL.

Statistical analyses were processed with IBM SPSS v.25.0 (IBM, Armonk, NY, USA). The chi-square test was used to assess differences in the frequency of individual prognostic factors. Univariate and multivariate analyses were performed according to Cox proportional hazards regression model. Survival rates were estimated with the Kaplan-Meier method and the differences were compared using a log-rank test. In Kaplan-Meier analysis the highest fifth (50\%) and the median (5.5\%) values were used as cut-off levels to divide the patients to high and low PD-L1 ${ }^{+} \mathrm{CD} 68^{+} / \mathrm{CD} 68^{+}$and IDO- $1^{+} \mathrm{CD} 68^{+} / \mathrm{CD} 68^{+}$ cell ratio subgroups, respectively.

Correlation analyses were performed with Spearman rank analysis. A level of probability below 0.05 was considered significant. All comparisons were two-tailed.

\section{Conclusions}

Earlier studies have highlighted the important role of TAMs in the pathogenesis of $\mathrm{cHL}$, as their high proportion has been associated with inferior outcomes. In this study we demonstrate for the first time that the adverse prognostic impact of TAMs on survival is checkpoint dependent, and more specifically PD-L1 and IDO-1 expression-dependent; high content of PD-L1 ${ }^{+}$and IDO- $1^{+}$TAMs in pretreatment tumor samples translates to poor survival in patients treated with standard chemoand radiotherapy. Our findings indicate that $\mathrm{PD}-\mathrm{L} 1^{+}$and IDO- $1^{+}$TAMs play important roles as 
immunomodulators in the TME and are potential new biomarkers for treatment stratification as well as potential new targets for novel immunotherapies.

Supplementary Materials: The following are available online at http://www.mdpi.com/2072-6694/12/4/877/s1. Figure S1: Correlation by Spearman rank analysis between gene and protein expression levels of macrophage markers, CD274/PD-L1 and IDO-1, Table S1: Correlations by spearman rank analysis between interferon gamma gene expression levels and different cell proportions in the mIHC analysis.

Author Contributions: Conceptualization, K.K., S.-K.L., T.P., S.L.; methodology, K.K., S.-K.L., O.B., M.-L.K.-L., S.M., T.P., S.L.; formal analysis, K.K., S.-K.L., S.M., T.P., S.L.; resources, O.B., M.-L.K.-L., S.M., T.P., S.L.; writing-original draft preparation, K.K., S.-K.L., T.P., S.L.; writing-review \& editing, K.K., S.-K.L., O.B., M.-L.K.-L., S.M., T.P., S.L.; supervision, T.P., S.L. All authors have read and agreed to the published version of the manuscript.

Funding: This research was funded by the grants from the Academy of Finland (S.L.), Finnish Cancer Organizations (S.L., S.M.), Sigrid Juselius Foundation (S.L., S.M.), University of Helsinki (S.L., S.M.), Helsinki University Hospital (S.L., S.M.), University of Helsinki, Doctoral Programme in Clinical Research (K.K.), Finnish Society for Oncology (K.K.) and Orion Research Foundation (K.K.).

Acknowledgments: We thank Petri Auvinen and Lars Paulin (Institute of Biotechnology, University of Helsinki, Finland) for the Nanostring analyses, Annabrita Schoonenberg (Institute for Molecular Medicine Finland) and the Digital and Molecular Pathology Unit supported by Helsinki University and Biocenter Finland for the mIHC stainings. Anne Aarnio and Marika Tuukkanen are acknowledged for technical assistance. Open access funding was provided by University of Helsinki.

Conflicts of Interest: S.L.: Janssen-Cilag: Consultancy, Research Funding*; Novartis: Concultancy; Roche: Consultancy, Honoraria, Research Funding*; Takeda: Consultancy, Honoraria, Research Funding; Merck: Consultancy, Honoraria; Bayer: Research Funding*; Celgene: Honoraria, Research Funding*. S.M: Novartis: Honoraria, Research Funding*; BMS: Honoraria, Research Funding*; Pfizer: Honoraria, Research Funding*. K.K. Sanofi-Genzyme: Travel and conference expenses; Janssen-Cilag: Travel and conference expenses; MSD: Travel and conference expenses; Gilead: Travel and conference expenses. The other authors declare that they have no conflict of interest. *Not related to this study.

\section{References}

1. Vardhana, S.; Younes, A. The immune microenvironment in Hodgkin lymphoma: T cells, B cells, and immune checkpoints. Haematologica 2016, 101, 794-802. [CrossRef] [PubMed]

2. Steidl, C.; Connors, J.M.; Gascoyne, R.D. Molecular pathogenesis of Hodgkin's lymphoma: Increasing evidence of the importance of the microenvironment. J. Clin. Oncol. 2011, 29, 1812-1826. [CrossRef] [PubMed]

3. Aldinucci, D.; Celegato, M.; Casagrande, N. Microenvironmental interactions in classical Hodgkin lymphoma and their role in promoting tumor growth, immune escape and drug resistance. Cancer Lett. 2016, 380, 243-252. [CrossRef] [PubMed]

4. Roemer, M.G.; Advani, R.H.; Ligon, A.H.; Natkunam, Y.; Redd, R.A.; Homer, H.; Connelly, C.F.; Sun, H.H.; Daadi, S.E.; Freeman, G.J.; et al. PD-L1 and PD-L2 genetic alterations define classical Hodgkin lymphoma and predict outcome. J. Clin. Oncol. 2016, 34, 2690-2697. [CrossRef] [PubMed]

5. Liu, W.R.; Shipp, M.A. Signaling pathways and immune evasion mechanisms in classical Hodgkin lymphoma. Hematol. Am. Soc. Hematol. Educ. Program 2017, 1, 310-316. [CrossRef]

6. Pedoeem, A.; Azoulay-Alfaguter, I.; Strazza, M.; Silverman, G.J.; Mor, A. Programmed death-1 pathway in cancer and autoimmunity. Clin. Immunol. 2014, 153, 145-152. [CrossRef]

7. Carey, C.D.; Gusenleitner, D.; Lipschitz, M.; Roemer, M.G.M.; Stack, E.C.; Gjini, E.; Hu, X.; Redd, R.; Freeman, G.J.; Neuberg, D.; et al. Topological analysis reveals a PD-L1-associated microenvironmental niche for Reed-Sternberg cells in Hodgkin lymphoma. Blood 2017, 130, 2420-2430. [CrossRef]

8. Li, F.; Zhang, R.; Li, S.; Liu, J. IDO1: An important immunotherapy target in cancer treatment. Int. Immunopharmacol. 2017, 47, 70-77. [CrossRef]

9. Prendergast, G.C.; Smith, C.; Thomas, S.; Mandik-Nayak, L.; Laury-Kleintop, L.; Metz, R.; Muller, A.J. Indoleamine 2,3-dioxygenase pathways of pathogenic inflammation and immune escape in cancer. Cancer Immunol. Immunother. 2014, 63, 721-735. [CrossRef] 
10. Hollander, P.; Kamper, P.; Smedby, K.E.; Enblad, G.; Ludvigsen, M.; Mortensen, J.; Amini, R.M.; Hamilton-Dutoit, S.; d'Amore, F.; Molin, D.; et al. High proportions of PD-1(+) and PD-L1(+) leukocytes in classical Hodgkin lymphoma microenvironment are associated with inferior outcome. Blood Adv. 2017, 1, 1427-1439. [CrossRef]

11. Choe, J.Y.; Yun, J.Y.; Jeon, Y.K.; Kim, S.H.; Park, G.; Huh, J.R.; Oh, S.; Kim, J.E. Indoleamine 2,3-dioxygenase (IDO) is frequently expressed in stromal cells of Hodgkin lymphoma and is associated with adverse clinical features: A retrospective cohort study. BMC Cancer 2014, 14, 335. [CrossRef] [PubMed]

12. Steidl, C.; Lee, T.; Shah, S.P.; Farinha, P.; Han, G.; Nayar, T.; Delaney, A.; Jones, S.J.; Iqbal, J.; Weisenburger, D.D.; et al. Tumor-associated macrophages and survival in classic Hodgkin's lymphoma. N. Engl. J. Med. 2010, 362, 875-885. [CrossRef] [PubMed]

13. Kamper, P.; Bendix, K.; Hamilton-Dutoit, S.; Honore, B.; Nyengaard, J.R.; d'Amore, F. Tumor-infiltrating macrophages correlate with adverse prognosis and Epstein-Barr virus status in classical Hodgkin's lymphoma. Haematologica 2011, 96, 269-276. [CrossRef] [PubMed]

14. Koh, Y.W.; Park, C.S.; Yoon, D.H.; Suh, C.; Huh, J. CD163 expression was associated with angiogenesis and shortened survival in patients with uniformly treated classical Hodgkin lymphoma. PLoS ONE 2014, 9, e87066. [CrossRef]

15. Guo, B.; Cen, H.; Tan, X.; Ke, Q. Meta-analysis of the prognostic and clinical value of tumor-associated macrophages in adult classical Hodgkin lymphoma. BMC Med. 2016, 14, 159. [CrossRef]

16. Tan, K.L.; Scott, D.W.; Hong, F.; Kahl, B.S.; Fisher, R.I.; Bartlett, N.L.; Advani, R.H.; Buckstein, R.; Rimsza, L.M.; Connors, J.M.; et al. Tumor-associated macrophages predict inferior outcomes in classic Hodgkin lymphoma: A correlative study from the E2496 Intergroup trial. Blood 2012, 120, 3280-3287. [CrossRef]

17. Gotti, M.; Nicola, M.; Lucioni, M.; Fiaccadori, V.; Ferretti, V.; Sciarra, R.; Costanza, M.; Bono, E.; Molo, S.; Maffi, A.; et al. Independent prognostic impact of tumour-infiltrating macrophages in early-stage Hodgkin's lymphoma. Hematol. Oncol. 2017, 35, 296-302. [CrossRef]

18. Sanchez-Espiridion, B.; Martin-Moreno, A.M.; Montalban, C.; Medeiros, L.J.; Vega, F.; Younes, A.; Piris, M.A.; Garcia, J.F. Immunohistochemical markers for tumor associated macrophages and survival in advanced classical Hodgkin's lymphoma. Haematologica 2012, 97, 1080-1084. [CrossRef]

19. Azambuja, D.; Natkunam, Y.; Biasoli, I.; Lossos, I.S.; Anderson, M.W.; Morais, J.C.; Spector, N. Lack of association of tumor-associated macrophages with clinical outcome in patients with classical Hodgkin's lymphoma. Ann. Oncol. 2012, 23, 736-742. [CrossRef]

20. Kayal, S.; Mathur, S.; Karak, A.K.; Kumar, L.; Sharma, A.; Bakhshi, S.; Raina, V. CD68 tumor-associated macrophage marker is not prognostic of clinical outcome in classical Hodgkin lymphoma. Leuk. Lymphoma 2014, 55, 1031-1037. [CrossRef]

21. Cencini, E.; Fabbri, A.; Rigacci, L.; Lazzi, S.; Gini, G.; Cox, M.C.; Mancuso, S.; Abruzzese, E.; Kovalchuk, S.; Goteri, G.; et al. Evaluation of the prognostic role of tumour-associated macrophages in newly diagnosed classical Hodgkin lymphoma and correlation with early FDG-PET assessment. Hematol. Oncol. 2017, 35, 69-78. [CrossRef] [PubMed]

22. Xiong, H.; Mittman, S.; Rodriguez, R.; Moskalenko, M.; Pacheco-Sanchez, P.; Yang, Y.; Nickles, D.; Cubas, R. Anti-PD-L1 treatment results in functional remodeling of the macrophage compartment. Cancer Res. 2019, 79, 1493-1506. [CrossRef] [PubMed]

23. Koh, Y.W.; Jeon, Y.K.; Yoon, D.H.; Suh, C.; Huh, J. Programmed death 1 expression in the peritumoral microenvironment is associated with a poorer prognosis in classical Hodgkin lymphoma. Tumour Biol. 2016, 37, 7507-7514. [CrossRef] [PubMed]

24. Pollari, M.; Bruck, O.; Pellinen, T.; Vahamurto, P.; Karjalainen-Lindsberg, M.L.; Mannisto, S.; Kallioniemi, O.; Kellokumpu-Lehtinen, P.L.; Mustjoki, S.; Leivonen, S.K.; et al. PD-L1(+) tumor-associated macrophages and PD-1(+) tumor-infiltrating lymphocytes predict survival in primary testicular lymphoma. Haematologica 2018, 103, 1908-1914. [CrossRef] [PubMed]

25. Scott, D.W.; Steidl, C. The classical Hodgkin lymphoma tumor microenvironment: Macrophages and gene expression-based modeling. Hematol. Am. Soc. Hematol. Educ. Program 2014, 2014, 144-150. [CrossRef] [PubMed] 
26. Chetaille, B.; Bertucci, F.; Finetti, P.; Esterni, B.; Stamatoullas, A.; Picquenot, J.M.; Copin, M.C.; Morschhauser, F.; Casasnovas, O.; Petrella, T.; et al. Molecular profiling of classical Hodgkin lymphoma tissues uncovers variations in the tumor microenvironment and correlations with EBV infection and outcome. Blood 2009, 113, 2765-3775. [CrossRef]

27. Vari, F.; Arpon, D.; Keane, C.; Hertzberg, M.S.; Talaulikar, D.; Jain, S.; Cui, Q.; Han, E.; Tobin, J.; Bird, R.; et al. Immune evasion via PD-1/PD-L1 on NK cells and monocyte/macrophages is more prominent in Hodgkin lymphoma than DLBCL. Blood 2018, 131, 1809-1819. [CrossRef]

28. Ansell, S.M.; Lesokhin, A.M.; Borrello, I.; Halwani, A.; Scott, E.C.; Gutierrez, M.; Schuster, S.J.; Millenson, M.M.; Cattry, D.; Freeman, G.J.; et al. PD-1 blockade with nivolumab in relapsed or refractory Hodgkin's lymphoma. N. Engl. J. Med. 2015, 372, 311-319. [CrossRef]

29. Armand, P.; Shipp, M.A.; Ribrag, V.; Michot, J.M.; Zinzani, P.L.; Kuruvilla, J.; Snyder, E.S.; Ricart, A.D.; Balakumaran, A.; Rose, S.; et al. Programmed death-1 blockade with pembrolizumab in patients with classical Hodgkin lymphoma after brentuximab vedotin failure. J. Clin. Oncol. 2016, 34, 3733-3739. [CrossRef]

30. Younes, A.; Santoro, A.; Shipp, M.; Zinzani, P.L.; Timmerman, J.M.; Ansell, S.; Armand, P.; Fanale, M.; Ratanatharathorn, V.; Kuruvilla, J.; et al. Nivolumab for classical Hodgkin's lymphoma after failure of both autologous stem-cell transplantation and brentuximab vedotin: A multicentre, multicohort, single-arm phase 2 trial. Lancet Oncol. 2016, 17, 1283-1294. [CrossRef]

31. Chen, R.; Zinzani, P.L.; Fanale, M.A.; Armand, P.; Johnson, N.A.; Brice, P.; Radford, J.; Ribrag, V.; Molin, D.; Vassilakopoulos, T.P.; et al. Phase II study of the efficacy and safety of pembrolizumab for relapsed/refractory classic Hodgkin lymphoma. J. Clin. Oncol. 2017, 35, 2125-2132. [CrossRef] [PubMed]

32. Brockelmann, P.J.; Engert, A. Checkpoint inhibition in Hodgkin lymphoma-A review. Oncol. Res. Treat. 2017, 40, 654-660. [CrossRef]

33. Gay, N.D.; Okada, C.Y.; Chen, A.I.; Scott, E.C. Targeting the programmed cell death 1 pathway in Hodgkin lymphoma: The place of nivolumab. Ther. Adv. Hematol. 2017, 8, 175-180. [CrossRef] [PubMed]

34. Meti, N.; Esfahani, K.; Johnson, N.A. The role of immune checkpoint inhibitors in classical Hodgkin lymphoma. Cancers (Basel) 2018, 10, e.204. [CrossRef] [PubMed]

35. Gordon, S.R.; Maute, R.L.; Dulken, B.W.; Hutter, G.; George, B.M.; McCracken, M.N.; Gupta, R.; Tsai, J.M.; Sinha, R.; Corey, D.; et al. PD-1 expression by tumour-associated macrophages inhibits phagocytosis and tumour immunity. Nature 2017, 545, 495-499. [CrossRef]

36. Komiya, T.; Huang, C.H. Updates in the clinical development of epacadostat and other indoleamine 2,3-dioxygenase 1 inhibitors (IDO1) for human cancers. Front. Oncol. 2018, 8, 423. [CrossRef]

37. Leivonen, S.K.; Pollari, M.; Bruck, O.; Pellinen, T.; Autio, M.; Karjalainen-Lindsberg, M.L.; Mannisto, S.; Kellokumpu-Lehtinen, P.L.; Kallioniemi, O.; Mustjoki, S.; et al. T-cell inflamed tumor microenvironment predicts favorable prognosis in primary testicular lymphoma. Haematologica 2019, 104, 338-346. [CrossRef]

38. Carpenter, A.E.; Jones, T.R.; Lamprecht, M.R.; Clarke, C.; Kang, I.H.; Friman, O.; Guertin, D.A.; Chang, J.H.; Lindquist, R.A.; Moffat, J.; et al. CellProfiler: Image analysis software for identifying and quantifying cell phenotypes. Genome Biol. 2006, 7, R100. [CrossRef]

(C) 2020 by the authors. Licensee MDPI, Basel, Switzerland. This article is an open access article distributed under the terms and conditions of the Creative Commons Attribution (CC BY) license (http://creativecommons.org/licenses/by/4.0/). 